\section{Reformas curriculares 2006- 2014: del ajuste pedagógico neoliberal a la reinstauración del modelo socialdemócrata}

RESUMEN

El presente artículo analiza las reformas curriculares implementadas en Costa Rica en el período comprendido entre los años 2006 y 2014, bajo la premisa de que estas responden a una reinstauración del Modelo Pedagógico Socialdemócrata vigente en el país entre 1957-1985. Para el desarrollo de dicho estudio se construye una definición desde un currículo crítico que enmarca el proceso de creación de una nueva interpretación de los períodos que integran la historia educativa posindependencia para examinar las características del Modelo Pedagógico Socialdemócrata y el Ajuste Pedagógico Neoliberal. Finalmente se indaga en las reformas implementadas en el período en estudio para debatir las implicaciones de la premisa desarrollada en el artículo para los sectores progresistas del sistema educativo.

Palabras Clave

Currículo; socialdemocracia; neoliberalismo; progresismo
Curricular Reforms 2006-2014: From the Neoliberal Pedagogical Adjustement to the Restoration of the Social Democrat Educational Model

ABSTRACT

The present essay makes an analysis of the curricular reforms implemented in Costa Rica in the period between 2006 and 2014, under the premise that these answer to the establishment of the Social Democrat Educational Model, which was active in the country between 1957 and 1985. To perform this analysis, a definition is built from the critical curriculum that frames the creation process of a new interpretation of the periods that integrate the educational history post-independence so that, afterwards, there is an analysis of the Social Democrat Educational Model features and the Neoliberal Pedagogical Adjustment, to finally enquire on the implemented reforms in the period under study and discuss the implications of the premise developed in the essay for the progressive sectors of the educational system.

KEY WORDS

Currículo; Social Democracy; Neoliberalism; Progressivism
Artículo recibido: 30 de enero del 2015. Evaluado:

2 de marzo del 2015.

Aceptado:

15 de marzo del 2015

Máster en Planificación Curricular, en la Universidad de Costa Rica. Asesor Nacional en Currículum, Consejo Nacional de Enseñanza Superior Universitaria Privada del Ministerio de Educación Pública de Costa Rica. Coordinador Proyecto Sortilegios Educativos. Correo electrónico: cesartoruno@gmail.com

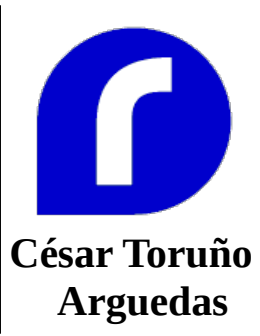




\section{Reformas curriculares 2006-2014: del ajuste pedagógico neoliberal a la reinstauración del modelo pedagógico socialdemócrata}

\section{Introducción}

El 19 de febrero del año 2014, a menos de dos semanas de finalizadas las elecciones nacionales cuyo resultado deparó una segunda ronda entre el candidato del Partido Liberación Nacional (partido en el poder desde el 2006) y el candidato del Partido Acción Ciudadana (partido de oposición), el periódico La Nación (periódico emblema del principal grupo de medios de comunicación del país e históricamente ligado con un proyecto hegemónico conservador y capitalista), publicó un editorial denominado "Ocho años de avance educativo" (La Nación, 2014) en el cual no solo reconocen los esfuerzos de la administración Garnier Rímolo y las mejoras en el sistema educativo, sino que indican que estos esfuerzos "alumbran el camino por seguir".

El editorial permite, al menos, dos interpretaciones desde una posición crítica al proyecto hegemónico implementado en Costa Rica. La primera establece que este editorial es una legitimación del grupo económico-político ligado al proyecto hegemónico neoliberal, en el tanto las reformas educativas comprendidas entre el 2006 y el 2014 forman parte del Ajuste Pedagógico Neoliberal; esta interpretación (del sistema educativo sometido al proyecto hegemónico neoliberal) ha sido ampliamente aceptada y repetida por diversos sectores con posiciones contrarias o críticas a dicho modelo económico. 
Sin embargo, existe una segunda interpretación en la que el editorial representa un punto de inflexión en la política educativa costarricense posterior a la década de 1980; en tanto, simbólicamente, los grupos hegemónicos explicitan el respaldo a una propuesta educativa socialdemócrata que difiere, en aspectos medulares, del Ajuste Pedagógico Neoliberal impulsado desde la década de 1980, y la cual es una actualización del modelo educativo socialdemócrata vigente en Costa Rica desde 1957 hasta 1985.

El presente ensayo asume la segunda premisa, para lo cual se realizará una construcción conceptual del currículo desde una pedagogía crítica, que sirve como marco de interpretación a una nueva propuesta de división de la historia educativa elaborada a partir de la construcción del currículo como área técnica de la pedagogía y herramienta de estructuración, control y seguimiento de la estructura educativa. Posteriormente, se profundizará en lo que el presente artículo denomina Modelo Pedagógico Socialdemócrata (incluyendo un apartado del Ajuste Pedagógico Neoliberal) como referente histórico y educativo para el análisis de las reformas implementadas durante las administraciones de Leonardo Garnier Rímolo (2006-2010 y 2010-2014) para establecer las implicaciones que tendría esta premisa (las reformas curriculares 2006-2014 como una reinstauración del Modelo Pedagógico Socialdemócrata) para el sector educativo progresista.

\section{El currículo y la pedagogía crítica: un producto contextual para la interpretación crítica}

El currículo es un producto cultural (Apple, 1997), un espacio de investigación y de redes de poder (Kemmis, 1998) donde hay visiones, ideologías intereses ocultos (Torres, 1998). Es una organización del conocimiento oficial (Apple, 1996a; 1996b) y una estructuración de un modelo cultural mediante el sistema educativo (Gimeno, 2001), escenario entre las resistencia y el proyecto hegemónico (Gimeno, 1998; Torres, 2001) y estructurado, durante gran parte del siglo XX, a los intereses de los poderes económicos capitalistas (Gimeno, 1997) y contra las clases populares (Freire, 1984); por tanto, se trata de una forma de estructurar, sistematizar, controlar, ordenar y evaluar el sistema educativo a partir de condicionantes históricas, sociales, culturales, políticas y económicas.

Al mismo tiempo, el análisis curricular entraña una compleja acción dialéctica de interacciones entre sociedad, cultura y educación. Se entiende esta última como un escenario eminentemente político (Freire, 1990) con posibilidades de resistencia (McLaren, 1995), un lenguaje de esperanza (Giroux, McLaren; 1998) y organización comunal (Freire, 1997) donde es posible la visibilización de las redes de poder y el papel asignado al sistema educativo en diferentes proyectos hegemónicos tanto explícitos como parte del Currículo Oculto (Torres, 1998). Es relevante en particular el estudio de este último en la era de la 
globalización y el neoliberalismo (Torres, 2001), economías de libre mercado, transnacionales y transformación de las políticas de Estado (Apple, 1996a, 1997).

Por tanto, el análisis del currículo costarricense y sus posibilidades de mejora debe asumir el reto de develar esos contextos, redes de poder y los fines asignados para generar una comprensión real de la estructura educativa. Esto a partir de la pedagogía crítica en tanto, en "la teoría tradicional del currículo, no se tiene conciencia de los tipos de conflicto que se dan en las escuelas en relación a diferentes formas de conocimiento" (Giroux y McLaren, 1998, p. 80).

Como bien afirma Giroux (2006, p. 205), "Ias escuelas no son ideológicamente inocentes, y tampoco son simplemente reproductoras de las relaciones e intereses sociales dominantes", por lo cual resulta necesario realizar los análisis para develar el papel del Estado, los grupos de presión y la estructura política en la estructuración del sistema educativo para establecer la interacción en la construcción de condiciones para la producción y adquisición del aprendizaje (Giroux, 1997).

Por lo tanto, a partir de la pedagogía crítica, se concibe que el currículo como un producto cultural no neutral, objetivo o técnico aislado de los procesos socioeconómicos; por el contrario, es la manifestación explícita de un proyecto cultural, social, político y económico que se estructura contextual e históricamente determinado dentro de la interacción dialéctica Sociedad-Sistema Educativo que, a su vez, genera marcos conceptuales y reguladores para la conformación tangible e intangible del sistema escolar y que, por lo tanto, se configura como un escenario de resistencias al proyecto hegemónico vigente.

En el marco de la anterior conceptualización, el presente ensayo abordará un análisis del currículo costarricense en interrelación con el contexto socio histórico, económico y cultural, estableciendo una nueva división de la historia educativa que permitirá analizar el Modelo Pedagógico Socialdemócrata, sus características y su influencia en el sistema educativo en la actualidad como primer paso para la denuncia y construcción de un modelo pedagógico ligado con el progresismo educativo.

Resulta necesario acotar que, para efectos del presente ensayo, el progresismo educativo se comprende como aquel grupo de personas ligadas al sistema educativo cuyas tesis de acción-reflexión son antimperialistas y están contra el proyecto político-económico neoliberal denunciando y resistiendo los poderes fácticos. Este grupo promueve modelos vivenciales-participativos de democracia. Además sus tesis cuentan con propuestas para la eliminación de la desigualdad social y marcos culturales e institucionales para la igualdad, la inclusión y la solidaridad. Asimismo, son ellos constructores de un currículo democrático así como de una redistribución del poder educativo que apunta a la construcción de medidas para asegurar al estudiante como cons- 
tructor activo del proceso de aprendizaje (coherente con una propuesta de mediación dentro del constructivismo y socioconstructivismo). A la vez dichas tesis de acción-reflexión defienden a los(as) docentes como intelectuales transformadores en un sistema educativo pensado desde y para la integralidad; todo esto dentro de los marcos de la pedagogía crítica.

\section{Nueva interpretación de la historia educativa: una división por modelos curriculares}

La comprensión del sistema educativo costarricense se ha realizado desde una división histórica-contextual ligada a una fragmentación histórica; en estos casos resulta referente el estudio realizado por Dengo (2011) y el realizado por Molina (2007), este último establece tres períodos de la Educación Costarricense, a saber: municipal-eclesiástico (1821-1885), el centralizadosecular (1886-1939) y el universitario-pedagógico (1940 en adelante). No obstante, la posición curricular esbozada en líneas previas exige la lectura de la división de la historia de la educación en relación con su funcionalidad dentro de un proyecto económico-político dominante.

Por lo tanto, el presente estudio dividirá la historia del sistema educativo costarricense a partir del desarrollo y consolidación de un modelo curricular, correlacionado al contexto socioeconómico y cultural de la sociedad. A partir de esta visión, la historia educativa se divide en tres grandes etapas: a) Originaria (1821-1885), b) Técnico-Liberal (1886-1956) y c) Modelo Socialdemócrata (1957-actualidad), este último con un período de Ajuste Pedagógico Neoliberal (1986-2005).

Las características de la educación costarricense entre 1814 y 1914 han sido estudiadas por Camacho (2005). Para el caso del presente artículo, podemos caracterizar la primera etapa, posindependencia, a partir de una ubicación temporal desde 1821 hasta 1885, con un sistema educativo a las órdenes de una economía agraria, aliada y controlada por el conservadurismo religioso (destacando el Concordato de 1852 el cual le confiere una alta cuota de poder a la iglesia Católica sobre el sistema educativo costarricense). Había en ese momento una organización centralizada, dedicada a la enseñanza de destrezas y conocimientos básicos (matemáticas y español para la interacción social y económica de la época) así como de valores patriarcales-religiosos y operacionalizada en la educación primaria, principalmente entre primer y tercer grado de la escuela.

La segunda etapa, Técnico-Liberal, se extiende desde 1886 (aprobación de la reforma educativa liberal) hasta 1956 (año previo a la aprobación de la Ley Fundamental de Educación). Se caracteriza por la vinculación del sistema educativo al proyecto liberal y su objetivo de formación de ciudadanos productivos con cultura universal, defensores y participantes activos del sistema 
democrático. Esta etapa contó con la ampliación de la matrícula en primaria (tanto niños como niñas) y la feminización del cuerpo docente de primaria (Molina y Palmer, 2000).

El currículo y la educación, en general, adquieren por primera vez un papel protagónico y estructurado en un proyecto hegemónico ligado a la consolidación del Estado nacional costarricense y el proyecto Liberal, por lo que el currículo evoluciona a la inclusión de nuevas asignaturas (como Cívica) y contenidos de la "cultura universal", la laicidad como principio organizador de la administración y de la selección de contenidos, ampliación de la oferta y la cobertura de la educación secundaria y, por último, a una profesionalización en la formación docente, siendo referente la creación de la Escuela Normal.

La tercera etapa del sistema educativo, Modelo Pedagógico Socialdemócrata, se extiende desde 1957 (aprobación de la Ley Fundamental de Educación) hasta nuestros días, con un Ajuste Pedagógico Neoliberal entre 1986 y el 2005. Durante la primera etapa de este período, 1957- 1985, el sistema educativo estuvo vinculado al Estado Desarrollista impulsado por el Partido Liberación Nacional constituyéndose en un gran movilizador social sustentado en la concepción de una educación para la formación de ciudadanos comprometidos con su patria, comunidad y productividad, solidarios y productoconstructores de una herencia cultural (fines de la educación establecidos en la Ley Fundamental de Educación). Se muestra en esta etapa un crecimiento en la cobertura de la educación secundaria y universitaria, esta última con la expansión de la cobertura de la Universidad de Costa Rica (creada en 1940) y creación de la Universidad Nacional (1973), el Instituto Tecnológico de Costa Rica (1971) y la Universidad Estatal a Distancia (1977).

Con respecto a esta propuesta curricular, se crearon o reforzaron las asignaturas de las ciencias sociales (Estudios Sociales y Filosofía), las artes (Música y Artes Plásticas) y la vida cotidiana (Educación Física, Hogar y Artes Industriales), se priorizó la ampliación de la oferta en secundaria con la inclusión de la educación técnica. Por otra parte, la profesionalización docente se da desde las universidades públicas (mejorando el dominio de contenido y técnicas para la mediación del aprendizaje) y se inicia una restructuración de la organización administrativa para responder a un nuevo currículo sustentado en los principios de Tyler (1973).

El Modelo Pedagógico Socialdemócrata sufrió las consecuencias de la crisis de 1978-1982 y el debilitamiento del Estado Interventor-Empresario, lo cual se tradujo en el surgimiento de una subetapa del sistema educativo, el Ajuste Pedagógico Neoliberal. Se puede considerar subetapa en tanto no logra consolidarse como un modelo educativo pero ejerce cambios en elementos fundamentales del Modelo Educativo Socialdemócrata. A continuación, se abordarán las principales características del Modelo Educativo Socialdemócrata desarrollado pos Guerra Civil y hasta el primer quinquenio de la década de 
los ochenta, esto como referente histórico de la reinstauración del modelo después del año 2006.

\section{Modelo Pedagógico Socialdemócrata}

La década de 1940 estuvo marcada por las reformas legales, administrativas y sociales ligadas a las Garantías Sociales y la lucha de la oligarquía contra dichas garantías, sumada a la organización de grupos insatisfechos con el transcurrir del país en una economía agroexportadora y liberal. Entre estos grupos destacó el Centro para el Estudio de los Problemas Nacionales. En el caso de dicho Centro, como afirma Miranda (2010), desde la década de 1940 propulsó una reforma educativa en primaria para adaptar los currículos a las zonas urbanas y rurales, mientras que en secundaria se optaba por una formación humanista complementada con orientación científica e incorporación de la educación vocacional.

Al finalizar la década, y como producto de la reconfiguración de fuerzas posGuerra Civil, el grupo hegemónico agroexportador-liberal fue sustituido por un grupo emergente representado por el Centro para el Estudio de los Problemas Nacionales (grupo Intelectual), el Ejército de Liberación Nacional (brazo armado) y, finalmente, por el Partido Liberación Nacional (brazo político que unificaría a los anteriores, a los grupos de la sociedad civil y a los pequeños partidos centristas). Como establece Rovira (2000, p.63), el Partido Liberación Nacional toma el poder en "una sociedad típicamente agro-exportadora que enviaba al exterior café, bananos y un poco de cacao y tenía que importar gran parte de todo lo que consumía". Frente a esa realidad, el Partido Liberación Nacional y grupos aliados, implementan el modelo desarrollista de intervención estatal (vigente entre 1949 e inicios de la crisis económica de la década de 1980), sustentado en la ideología socialdemócrata.

Rovira (2000) caracteriza al proyecto socialdemócrata a partir de sus esfuerzos para la diversificación de la producción; la participación de otros sectores en la producción; la relación del cooperativismo y pequeña propiedad; el Estado como organizador del sistema económico e impulso de la industrialización; la modernización del aparato estatal capitalista (creación de instituciones); la consolidación de una economía mixta; la consolidación de la clase media y de la nueva burguesía. En relación con este último apartado, Rovira (2000, p. 69) indica que un punto esencial de este modelo es "su política económica estructurada globalmente para diversificar la producción, fortalecer otros sectores y ramas de la economía e ir creando así nuevos grupos burgueses. Alrededor de esto es que gira todo lo demás".

Con respecto al sistema educativo, el estudio de García (2011) establece que al iniciar la década de 1950, Costa Rica tenía 975 centros de formación primaria (con una media de estudios en zonas rurales de 2,2 grados y en las 
ciudades de 4,3 grados), $2 \%$ de la población económicamente activa era docente, el alfabetismo promedio alcanzó el promedio de $78,76 \%$ de la población (en las ciudades era de 91,88\%), además existían 13 centros educativos de secundaria y $12 \%$ de la población había terminado estudios secundarios.

Además, el estudio de García (2011) aporta evidencia de que antes de 1950 se había dado la creación de colegios privados con un claro elemento segregador entre los hijos de la burguesía, clases medias y clases populares, así como el surgimiento, desde la década de 1930, de centros para la formación de oficios y profesiones como la Escuela de Comercio Castro Carazo, el Colegio Superior de Inglés y Ciencias Comerciales Manuel Aragón y la Escuela de Comercio de Limón. Estos dos elementos son aceptados en el Modelo Pedagógico Socialdemócrata (MPS), permitiendo la permanencia y leve expansión de los centros educativos privados e institucionalizando la formación para el trabajo mediante la creación del Instituto Nacional de Aprendizaje (INA) y la ampliación de la educación técnica, esto último en el marco de la inserción costarricense en el Mercado Común Centroamericano.

De esta manera, el MPS se le debe comprender como el instrumento cultural utilizado por el nuevo grupo dominante para legitimarse (mentalidad del colectivo) mediante la creación de un ciudadano acorde con la nueva estructura política y por medio de la formación de estudiantes en el marco de las nuevas expectativas culturales, ciudadanas y productivas, sin obviar su papel como un instrumento indispensable en la política de distribución de la riqueza dentro del esquema socialdemócrata de movilización social (ascenso en el nivel socioeconómico que podría tener una persona o familia a partir de una intervención del Estado). Como bien afirma Miranda (2010, p. 200), se define a la educación como "unidad ideológica para la configuración de la hegemonía política y cultural de orientación socialdemócrata y a la vez, de formación del ejército laboral de reserva calificada necesaria para las escalas laborales que requería el proceso de modernización capitalista".

El sistema educativo desde el MPS es consolidado a partir de la creación de la Ley Fundamental de Educación (1957) en tanto esta normativa establece los pilares de la estructura curricular vigente en Costa Rica hasta la actualidad. Entre los elementos más importantes están los siguientes: definición de la educación y el perfil de salida (es decir, las características que debe poseer cada estudiante al terminar la educación secundaria); estructuración por ciclos y asignaturas; institucionalización del Consejo Superior de Educación como ente rector del sistema con poder decisorio en el currículo nacional; y elementos básicos de la estructura administrativa. Adicionalmente, la educación es reformada en su función social en tanto, siguiendo a Fernández (2002), dentro del MPS esta se instituye en un instrumento de política de igualdad de oportunidades caracterizado por la inclusión, la educación compensatoria y especial, gratuidad en el sistema público o privado subvencionado y regulación para que no exista discriminación. 
EI MPS consolidó la gratuidad del sistema público de la Educación General Básica (ratificado en la Constitución Política) al tiempo que la educación compensatoria sustentó la creación de ofertas para adultos y alfabetización; la ampliación de la educación especial; la regulación de la educación privada; la ampliación de la inversión en infraestructura; la contratación docente para ampliar la educación secundaria; y las reformas curriculares para permitir un currículo con mayor sustento en la realidad costarricense; es decir, la realidad de un Estado con un proyecto económico intervencionista, el Modelo de Sustitución de Importaciones y la industrialización como objetivo de desarrollo.

EI MPS consolida, por primera vez en la historia del sistema educativo costarricense, un diseño curricular estructurado y fundamentado en el enfoque técnico, el cual mantendrá una vigencia parcial hasta nuestros días. Dicho enfoque, estructurado a partir de los aportes elaborados por Tyler (1973) para los Estados Unidos pos-Segunda Guerra Mundial, establece que el diseño del currículo se define a través de una serie de presupuestos como (a) el currículo es una organización de los procesos educativos para lograr una mejora en los procesos de enseñanza y aprendizaje; (b) se construye a partir de una serie de fundamentos y fuentes que establecen la concepción y relación del sistema educativo con la sociedad; (c) se construye a partir de la secuenciación del diseño curricular (selección de objetivos, selección y organización de las experiencias de aprendizaje y preparación de la evaluación); (d) el currículo es un área disciplinar, dentro de las áreas pedagógicas dirigido al estudio, diseño e implementación de las acciones y estrategias necesarias para convertir los conocimientos disciplinares y científicos en conocimientos para los estudiantes; (e) los fenómenos curriculares pueden racionalizarse, controlarse y medirse.

El enfoque técnico será complementado con un enfoque práctico sustentado en los postulados de Taba (1974) al crear una amalgama de enfoques curriculares propia de la realidad costarricense, por cuanto se debe comprender el currículo costarricense como una compleja red de elementos dinámicos y variantes que interactúan entre lo idealizado en documentos oficiales (enfoque curricular práctico ligado al constructivismo, del cual resulta referente la Política Educativa Hacia el Siglo XXI aprobada en 1994 y vigente a nuestros días) y la realidad de la contextualización curricular ligada al conductismo, la fragmentación de la organización administrativa-pedagógica y la priorización de los resultados, así como las demandas y proyectos específicos de grupos o personas ligadas a un enfoque sociocrítico.

Dicho lo anterior, podemos caracterizar el MPS como el modelo educativo implementado en Costa Rica posterior a la guerra civil (1948), ligado políticamente al Partido Liberación Nacional, sustentado en los preceptos de la Constitución (1949) y la división por ciclos y fines de la educación establecidos en la Ley Fundamental de Educación (1957), que asume la educación 
como instrumento de movilización social y distribución de la riqueza, con una función de educación integral (acercamiento a la cultura universal y desarrollo de una persona emocional y socialmente plena, según se puede inferir de los fines de la educación). Este modelo pedagógico está también ligado al nuevo modelo económico mediante la formación de mano de obra especializada (colegios vocacionales, colegios técnicos, inclusión de asignaturas como Mecanografía en el currículo de colegios académicos y el Instituto Nacional de Aprendizaje).

EI MPS se operacionalizó mediante el aumento de la inversión en educación; la conceptualización del dinero dedicado a educación como inversión; la ampliación de la cobertura en secundaria (objetivo de inclusión social, la movilización y construcción de legitimidad del proyecto político-económico); la nueva organización del Ministerio de Educación Pública (extrapolación empresarial del enfoque curricular técnico, correspondiente con la visión fragmentada y dirigida a maximizar el control-evaluación del producto educativo); el aumento de la estructuración de los procesos educativos (programas de estudio, materiales didácticos y otros); la fragmentación del conocimiento por asignaturas; los programas de equidad (para la inclusión y permanencia de estudiantes de estratos económicos medio-bajo y bajo); y la ampliación de la oferta académica según necesidades del nuevo modelo económico.

EI MPS postula la premisa de la importancia estratégica de la educación pública tanto para el Estado como para la sociedad y los individuos y su coherencia con la distribución de la riqueza desde el ideario socialdemócrata, por lo que logra constituir a la educación en una institución cultural impulsora de la narración que legitima el proyecto socioeconómico y defiende al proyecto hegemónico contra posibles resistencias tangibles o intangibles. Esto último adquiere relevancia en el marco de la abolición del ejército y la construcción del mito del "ejército de educadores"; una narración construida para visibilizar la importancia estratégica de la institución educativa.

\section{Ajuste Pedagógico Neoliberal}

Al finalizar la década de 1970, el Modelo de Estado Desarrollista o Interventor enfrentó una profunda crisis, cuyas causas y características trascienden el presente ensayo, pero su consecuencia intangible más importante fue la crisis de legitimidad (Miranda, 2007) del Modelo de Estado e, inherentemente, de los postulados argumentados por la socialdemocracia costarricense en las tres décadas anteriores.

Como consecuencia de la crisis económica y de legitimidad, junto al ascenso de las corrientes político-económicas de corte neoliberal impulsadas desde Estados Unidos, América Latina inicia la restructuración política y económica (con implicaciones socioculturales) denominado como Estado Neoliberal (Li- 
chstenztejn, 1988). Costa Rica implementa entonces las reformas dirigidas a la apertura comercial (Hidalgo, 1998) cuyas medidas económicas generaron un daño social e institucional (Korten, 1997), que todavía no ha sido reparado en aspectos como la desigualdad social, la exclusión de sectores populares, la disminución de la clase media y los mecanismos de movilidad social, la precarización laboral y otras que, en el fondo, constituirían una crisis de legitimidad que alcanzaría al propio modelo hegemónico (Vargas, 2002).

A nivel educativo, el modelo neoliberal introdujo una serie de reformas para el cambio de la concepción de la ciudadanía (Hindes, 2002) además del acercamiento de la formación al capitalismo y globalización (Miranda, 2001). A lo anterior se suma la disminución de las partidas dedicadas al área educativa aduciendo eficiencia presupuestaria (Pérez y González, 1991). Sin embargo, el presente ensayo delimita estas reformas bajo la denominación de Ajuste Pedagógico Neoliberal (Toruño, 2010, 2011) caracterizado por:

a) Una reforma económica singularizada por un cambio de concepción del dinero destinado a educación (de inversión a gasto); asimismo por la disminución de la inversión; la desregulación del sistema para impulsar la apertura (directa e indirecta) y ampliación de la cobertura de instituciones educativas privadas y la promoción de instituciones subvencionadas; la limitación en la contratación docente y en la infraestructura (generando un sobre poblamiento en las aulas); la priorización de inversión en área educativas "rentables" como Educación Técnica; y el aumento de la cantidad de días lectivos (y su correlación con una supuesta mejora en la calidad), entre otras

b) Una reforma institucional para aumentar eficiencia y eficacia, lo cual se tradujo en la creación-desarrollo de oficinas para el Control y la Calidad (en el caso de Evaluación) además de la profundización de la segmentación-especialización en oficinas centrales y las asignaturas de currículo. A lo anterior se añade la inserción de procesos de desarrollo-seguimiento-evaluación propios del sector privado. Se adiciona a esto, la creación de una oferta de modalidades educativas para "maximizar" los logros educativos y proyectos de Municipalización de la Educación (el principio de la descentralización ha sido fundamental dentro de la propuesta neoliberal iberoamericana) que han sido archivados por las resistencias sociales y políticas a esta medida.

c) Una reforma curricular que implicó cambios en contenidos y asignaturas dirigidas a la formación de un Consumidor-Trabajador (ser humano en la sociedad de consumo) en sustitución de la formación ciudadana (vivencia democrática). Se introdujeron también exámenes en sexto año, noveno año y bachillerato para verificar la calidad de la formación dada-recibida; se amplió la oferta técnica y se reorganizaron los contenidos-mediación para aumentar la "eficiencia" de los procesos educativos. Todo esto en coherencia con la Pedagogía por Objeti- 
vos (Gimeno, 1997) y la construcción de un productor-consumidor más que de un ciudadano (Toruño, 2010).

Sin embargo, a pesar de los esfuerzos de determinados sectores políticoeconómicos, el Ajuste Pedagógico Neoliberal no logró sustituir el Modelo Pedagógico Socialdemócrata, en tanto no implementó elementos básicos de una propuesta pedagógica neoliberal (Torres, 2001) como lo son la privatización o semiprivatización de gran parte de las instituciones educativas ni la desconcentración o municipalización del sistema educativo. De igual manera tampoco se desarrolló un sistema curricular fundamentado en las corrientes conservadoras ni se crearon ofertas educativas con sistemas de ingreso diferenciado (por ejemplo, educación técnica en zonas urbano marginales y científicos en zonas de clase media-alta). No se concretó un sistema flexible para la contratación de los trabajadores del sistema educativo (eliminación de la posibilidad de ser propietario en un puesto por tiempo indefinido, aumento de jornadas laborales, sistema de pago según evaluaciones, aumento de cantidad de estudiantes por grupo y eliminación de pluses como anualidades y carrera profesional) ni se eliminaron las asignaturas "inútiles" en la sociedad de mercado como tampoco las "distorsiones" provocadas por los programas de equidad.

Lo anterior no omite los impactos negativos del Ajuste Pedagógico Neoliberal para el sistema educativo costarricense entre los que se debe destacar el debilitamiento de la educación integral (en tanto se priorizó la enseñanza técnica, el inglés y la informática); la caída y el estancamiento de las tasas de cobertura en secundaria posterior a la crisis de la década de 1980; el cambio en lo conceptual del dinero dedicado a la educación como un gasto social; la disminución de los "gastos" en infraestructura, mobiliario y programas de equidad; la implementación de un sistema de evaluación segregador (pruebas nacionales en sexto, noveno y undécimo año) y conservador (introducción de la evaluación de la conducta y la correlación con las notas académicas); la sobrepoblación de centros educativos (producto de una baja en la inversión en infraestructura); el debilitamiento de los programas de equidad (menos inversión y disminución de la cobertura); la ampliación de la contratación interina dentro del Magisterio Nacional y el debilitamiento de su sistema de derechos-garantías. Un caso referente fue la afectación al régimen de pensiones que desembocó en uno de los mayores movimientos magisteriales en el año 1995, finalizando con la derrota del movimiento huelguístico y generando una década de debilitamiento y deslegitimización de las organizaciones sindicales magisteriales frente a sus bases. 


\section{La reinstauración del Modelo Pedagógico Socialdemócrata: el currículo oculto y explícito de las reformas}

Dos décadas después de iniciar su implementación, el Estado Neoliberal degeneró en una crisis de legitimidad política marcada por el aumento de la desigualdad, la conservación de índices de pobreza y la disminución de la movilidad social característica del Estado Interventor (principalmente entre 1950 y 1970) y la correlación entre el manejo del Estado y los intereses de sectores privados visibilizados en escándalos de corrupción.

El agotamiento del modelo partidario, la lucha contra el Combo del ICE en el año 2000, el aumento del abstencionismo, la ruptura del bipartidismo, la crisis política generada por el escándalo de corrupción que envolvió a líderes políticos entre el 2003 y 2005, la crisis de legitimidad de las instituciones democráticas y la lucha-polarización sobre el TLC con Estados Unidos demostraron que, en términos de Habermas (2008), nuestro sistema sufría una crisis de legitimidad y como crisis sociopolítica con fundamento cultural, la respuesta posible era en el marco de una reformulación de la formación ciudadana.

En este escenario, de crisis de legitimidad y polarización, asumió la Presidencia de la República Óscar Arias Sánchez (2006-2010), quien designó a Leonardo Garnier Rímolo como Ministro de Educación y quien fue ratificado durante la presidencia de la señora Laura Chinchilla Miranda (2010-2014). La administración de Leonardo Garnier (2006-2010, 2010-2014) realizó una serie de reformas dirigidas a la reformulación de la formación ciudadana, sin embargo, como se analizará en el siguiente apartado, este proceso implicó una transformación de la política educativa para dar paso a una reforma reinstaurativa del Modelo Pedagógico Socialdemócrata (MPS), que realiza rupturas conceptuales (educación como derecho e inversión) y reguladoras (asignaturas, contenidos, presupuesto y otras) con respecto al Ajuste Pedagógico Neoliberal imperante en las dos décadas anteriores.

Todo proceso de reforma curricular posee un currículo oculto (Torres, 1998) integrado por redes de poder invisibles (Gimeno, 1998), visión de la educación, propósitos del sistema, proyectos hegemónicos, ciudadanía esperada, entre otros. La visibilización del currículo oculto de una reforma enfrenta el desafío de que los análisis, generalmente, no cuentan con respaldo documental que permita el estudio de aspiraciones, ideales y redes de poder manifiestas fuera de los documentos oficiales.

En el caso de las reformas impulsadas bajo la administración de Leonardo Garnier, se puede realizar un análisis de las aspiraciones, concepción de ciudadanía y funciones educativas a partir de los artículos escritos por él como parte su columna semanal en el periódico la Nación, titulada "Sub-versiones". Estos escritos fueron elaborados entre el 2002 y abril de 2006 (período previo a su llegada al Ministerio de Educación Pública), en su calidad de figura pública relacionada con el Partido Liberación Nacional, publicados en un dia- 
rio ligado, tanto por el abordaje noticioso como por la red de negocios de sus accionistas, con el proyecto político-económico neoliberal y sin la posibilidad real, en el momento de escribir los textos (con excepción del último artículo vinculado al tema educativo, publicado en abril de 2006), de ejercer influencia sobre las reformas educativas en Costa Rica.

En sus textos, Garnier establece una ruptura con el discurso neoliberal de mercantilización de la educación y su priorización de la formación de mano de obra, rescatando la necesaria formación integral (con énfasis en lo artístico) al indicar que es necesario,

juntar la economía y el arte, la economía y la música, la economía y la plástica, la economía y... cualquier tipo de manifestación cultural, pero no en un sentido mercantilista miope... sino, por el contrario, entendiendo y atendiendo el carácter de bien eminentemente público que, por diversas razones, tiene la creación artística (Garnier, 2002a).

En ese artículo, se le da carácter de "transformadora" a la experiencia de disfrute y apreciación del arte, finalidad que será plasmada en las Reformas de Ética, Estética y Ciudadanía en Música y Artes Plásticas y en la creación del Festival Estudiantil de las Artes (FEA), ambas realizadas entre el año 2008 y 2009. Además, tanto el artículo como las reformas revalorizan el arte dentro del proceso educativo y plasman un anhelo del MPS (formación integral con el uso del arte como recurso indispensable), el cual alcanzó su mayor preponderancia durante el primer quinquenio de la década de 1970.

En segundo lugar, frente a la polémica suscitada a raíz de las declaraciones de autoridades del Ministerio de Educación Pública anteriores a su administración contra la asistencia de todos los niños(as) al comedor (en tanto el dinero no era suficiente y se debía priorizar a quienes en verdad lo necesitaban), Garnier (2002 b) reitera la crítica a la educación con el objetivo prioritario de la formación de mano de obra e introduce el tema de la convivencia al afirmar que:

La educación, para serlo, tiene que ir mucho más allá de la mera adquisición de conocimientos para la vida laboral. También debe enseñar a vivir -"aprender a comer de todo" como dijo una maestra- y, sobre todo, aprender a convivir, aprender que somos de los mismos, que la comida y la educación que compartimos es un derecho, no un privilegio ni una limosna. 
Lo anterior devela tres conceptos básicos del currículo oculto de las reformas realizadas durante su gestión: la educación para la convivencia, la educación para la vida y la educación pública como un derecho. Estos tres elementos constituyen la base del ideario pedagógico del MPS plasmado en la Ley Fundamental de Educación, principalmente referente a los fines del sistema educativo.

Amerita mención especial el caso de la educación para la convivencia, en tanto Garnier (2006) afirmó que:

Hemos cerrado y menospreciado los espacios para el juego, para el arte, para el deporte, para la música, para el teatro, para el campamento, para el entretenimiento, para la conversación, para la tertulia - hoy chat -, para el jolgorio, para la amistad. Hemos confundido jugar o divertirse con vagabundear. Al hacerlo, hemos ido minando aquello que más llena, que más vivifica, que mejor ocupa y apasiona a los jóvenes y, de paso, lo que más limita y evita la violencia, lo que la hace más absurda e innecesaria. Hemos cerrado los espacios de la ética y la estética, los espacios donde se aprende qué es bueno y correcto, qué es bello, bonito, entretenido.

La elaboración conceptual de una educación para la convivencia rompe con la visión tradicional-conservadora (una educación para obedecer y aprender) y neoliberal (una educación para el trabajo e individualizada), reivindicando las posturas progresistas en el área educativa vinculadas a la educación vivencial, construcción de vínculos, el espacio lúdico y la comprensión de los aprendizajes más allá de los contenidos disciplinares. Sin embargo, la ruptura más importante se realiza con la conceptualización de Violencia-Convivencia, asumiendo como prioridad la construcción de una convivencia desde el disfrute, la expresión, el encuentro y la ética-estética. La inclusión de este eje pedagógico constituye un paso adelante con respecto al MPS de las décadas anteriores y permite acercamientos con las posiciones del progresismo educativo del país al iniciar el siglo XXI.

En relación con la educación pública como derecho, se incluye la educación como el espacio de formación para la convivencia democrática (Garnier, 2002d), con la globalización y sus retos (Garnier, 2002c). Se visualiza también la necesidad de una ciudadanía práctica que trascienda la simple repetición de contenidos (Garnier, 2005a), entrelazada con la necesidad de universalizar la educación secundaria. En este sentido, Garnier (2005b) señaló que es importante: 
Frenar el desgrane empezando por sus discontinuidades álgidas. Resolver las carencias de primaria que promueven el fracaso en secundaria. Avanzar hacia una secundaria que resulte atractiva y útil para los estudiantes. Elevar la motivación, la formación y capacitación docente. Mejorar la infraestructura y el entorno de aprendizaje. Atender a los sectores y regiones más rezagados o con problemas especiales. Usar la evaluación como medio correctivo y no como autopsia. Aprovechar las nuevas tecnologías para el aprendizaje y, en especial, para cerrar brechas. Fortalecer los programas exitosos... y cerrar otros; etc. Todo ello exige invertir más en educación.

Las anteriores reflexiones se fundamentan, aunque no se mencione explícitamente, en los postulados básicos asignados a la educación dentro del modelo socialdemócrata implementado en Costa Rica entre la década de 1950 y finales de la década de 1970, a saber: (a) acceso universal con amplia participación estatal; (b) educación como espacio de formación ciudadana (ligada a la convivencia, el aprecio de las manifestaciones culturales y la acción en el ámbito político); (c) integrada dentro de modelo productivo que promueva la distribución de la riqueza; y (d) movilizador social.

Por lo tanto, los textos escritos por el señor Garnier entre el 2002 y 2006 develan un currículo oculto ligado al proyecto socialdemócrata y a su modelo pedagógico, cuyas premisas básicas se oponen al Ajuste Pedagógico Neoliberal y su concepción de ciudadanía (Toruño, 2010). Sin embargo, este currículo oculto encuentra manifestaciones explícitas en las reformas implementadas en el período comprendido entre el año 2006 y 2014.

Entre el 2006 y 2008 se desarrolló la base curricular para la reforma Ética, Estética y Ciudadanía la cual generó nuevos programas de estudio, estrategias de mediación (constructivistas) y evaluación en Educación Cívica (2009), Educación Musical (2008), Artes Plásticas (2009) y Educación Física (2010); como también una priorización de asignaturas consideradas "especiales" o "secundarias" en el ideario neoliberal. Además, se crean los programas de Pensamiento Científico (2008), se hacen reformas en Ciencias de primaria dirigidas a la inclusión de mediación para la construcción del pensamiento científico, y Piensa en Arte (2009), esta última en Español e implicó la creación de una lección para construir habilidades comunicativas a partir del conocimiento, aprecio y disfrute del arte. En el mismo período se crean el Festival Estudiantil de las Artes (2008) y El Cole en Nuestras Manos (proyecto que sería la antesala del Programa Convivir. Este último será oficializado 
en el año 2011. Además, se consolidan-expanden los Juegos Deportivos Estudiantiles, la Bandera Azul Ecológica y los Gobiernos Estudiantiles.

Durante la segunda administración (2010-2014) se realizaron las reformas sustentadas en los principios de Ética, Estética y Ciudadanía. En secundaria se realizaron las reformas en Vida Cotidiana (2012), Artes Industriales (2013) y Afectividad y Sexualidad Integral (2012). Esta última fue convertida en la reforma educativa más polémica durante las últimas décadas por el rechazo del sector más conservador del país. A nivel de primaria se realizaron las reformas de Español (2013), Artes Plásticas (2013), Educación Musical (2013), Educación Física (2013) y Estudios Sociales y Cívica (2013); en Preescolar (2014) y, en primaria-secundaria, la reforma de Matemáticas (2012).

A partir de un análisis de contenido de los programas de estudio de estas reformas, se puede concluir que estas tuvieron como ejes del currículo oculto el desarrollo de una serie de competencias vinculadas con la formación ciudadana en el marco de una visión del MPS (incluso involucrando elementos de la discusión de la Tercera Vía) con la incorporación de la Convivencia como elemento innovador y plasmadas tanto en contenidos como en el desarrollo de actividades de mediación e implementación de estrategias de evaluación. Entre estas competencias se encuentran comunicación, disenso, consenso, deliberación, toma de decisiones, negociación, comunicación social y política, participación, representación, trabajo en equipo, responsabilidad individual y social, resolución de problemas, saber elegir y disfrute de la diversidad.

Además de estos ejes, la administración utilizó cuatro pilares como principios implícitos en la selección y organización de contenidos, a saber: Conocer, Apreciar, Disfrutar y Expresar. Las implicaciones de estos pilares trascienden los límites tácitos del presente ensayo, sin embargo resulta necesario ampliar los debates curriculares sobre esta temática, las posibles transformaciones en el diseño curricular y la posible innovación para el MPS al incluir estos pilares como referentes para la selección y organización de contenidos, para las actividades de mediación y para los proyectos extra académicos.

La posición del señor Garnier y las anteriores reformas académicas implementadas entre el año 2006 y el 2014 son coherentes con el MPS, el perfil de ser humano a formar dentro de ese modelo pedagógico y el planteamiento del Congreso Ideológico del Partido Liberación Nacional del año 2005, en el cual se indica:

El sistema educativo debe apoyarse en los avances de las diferentes ciencias, las demandas del país y los cambios del mundo. Los factores científicos, tecnológicos y sociales deben conjugarse con un sólido desarrollo de los valores humanos, las artes y las letras deben ser objeto de permanente promoción y difusión. Especial estímu- 
lo ha de brindarse a las manifestaciones creadoras del pueblo y a toda forma de cultura que emane de él. Asimismo, la formación ciudadana debe tener la primera prioridad en el proceso educativo para preservar los valores cívicos y éticos, ennoblecer la acción política y dignificar su ejercicio. La educación debe ser relevante, con un sentido vivo de actualidad y utilidad. Esto incluye la educación para la salud; educación para la convivencia, para la vida en comunidad; educación para la recreación física y espiritual; educación para una vida en armonía con la naturaleza y el medio ambiente (Partido Liberación Nacional, 2005, p. 54; el resaltado en negrita para fines del presente artículo).

Lo anterior permite visibilizar el tejido conceptual y orgánico que constituye el currículo oculto de las reformas en estudio y que será manifiesto en los cambios académicos y extra académicos realizados. Estamos, pues, ante un claro proyecto educativo entramado en la lógica curricular del MPS y las necesidades de construir nuevos pactos, consensos y legitimidades dentro del proyecto hegemónico; un proyecto que no se limita a las reformas de programas de estudio porque se extendieron también programas extra académicos y marcos reguladores del sistema educativo.

La reforma al Reglamento de Evaluación de los Aprendizajes (2008), un acompañante clave en la propuesta pedagógica de la reinstauración del MPS, implicó un cambio de concepción de la evaluación dentro del sistema educativo puesto que eliminó tanto las Pruebas Nacionales de Sexto y Noveno Año como la Repetición Anual (antes de la reforma, si un estudiante perdía una o varias materias tenía que repetir todo el curso lectivo). Se introdujo además el Adelantamiento de materias (sólo se repiten las materias no aprobadas y se cursan las materias del año escolar siguiente, por ejemplo si un estudiante perdió Matemáticas en octavo año, repetirá esa materia en el siguiente curso lectivo y llevará las demás materias de noveno año). Se eliminó también la obligación de aprobar el último trimestre (con la antigua normativa si un estudiante de educación tenía como calificaciones 90 en el primer trimestre, 80 en el segundo y en el tercer trimestre obtenía una nota inferior al promedio mínimo -70 en educación diversificada y 65 en Tercer Ciclo-, la materia sería reprobada). Igualmente, se suprimió la vinculación Nota de Conducta y Notas Académicas (si un estudiante obtenía una nota inferior al mínimo en Conducta, tendría que realizar un examen de Convocatoria en todas las asignaturas con calificación inferior a 80 y repetiría el curso lectivo en caso de no aprobar las pruebas). 
A nivel de asignaturas, la reforma al Reglamento de Evaluación de Aprendizaje introdujo el cambio en diversas materias para incorporar la evaluación por proyectos (un 30\% o 35\% de la nota final en cada trimestre), lo cual constituyó un paso operativo hacia la implementación de una mediación constructivista en el tanto que, por primera vez, actividades como proyectos, trabajos cotidianos y extraclase tenían mayor importancia evaluativa que el examen tradicional. Este último fue reducido a solo uno por trimestre con un $35 \%$ como porcentaje máximo.

Lo anterior rompe con uno de los ejes del Ajuste Pedagógico Neoliberal producto del deseo de control y supervisión extrapolado desde el sector empresarial y los anhelos de "normalización" moral de los sectores conservadores. Además, con estos cambios se introduce un cuestionamiento al status quo (repetir un año por una materia) que no había sido abordado por los sectores progresistas del sistema educativo. Sin embargo, no se puede asumir como una reforma dirigida a esa ruptura; en tanto se debe considerar también las implicaciones de mantener una mayor cantidad de estudiantes en el sistema educativo y disminuir los índices de reprobación, ambos motivos relevantes desde una administración política del sistema.

Las reformas académicas, extra académicas y de evaluación, durante el período 2006 a 2014, fueron acompañadas de un giro en el financiamiento de la educación, alcanzando la cifra del 7,2\% del PIB para el año 2013, siendo uno de los elementos referentes del cambio en la concepción de la inversión el rubro de infraestructura educativa y mobiliario. Según datos del MEP (2014), entre el 2002 y 2006 la inversión en infraestructura fue de 16995 millones y en mobiliario de 3235 millones, en estos mismos rubros entre el 2007 y el 2010 la inversión fue de 110464 millones y 8654 millones respectivamente, mientras que entre el 2011 y el 2014 fue de 135251 millones y 7441 millones respectivamente. A lo precedente se debe sumar la aprobación de un fideicomiso en el 2014 por un monto de 167 millones de dólares para la construcción de infraestructura educativa.

A nivel de los denominados Programas de Equidad, entre los años 2005 y el 2014, el Estado paso de invertir 11300 millones en el Programa de Comedores Escolares a 52500 millones de colones, con una cobertura de más de 673 mil estudiantes durante el año 2013. Con respecto a la inversión en transporte, en el año 2006 se dirigieron a este 5941 millones y en el año 2014 alcanzó la cifra de 24693 millones mientras que el sistema de becas de FONABE pasó de una cobertura de 139537 estudiantes en el año 2006 (con una inversión de 5694 millones) a 198236 en el año 2014 (una inversión de 46927 millones de colones).

Relacionado con las tasas de asistencia, cobertura y brechas educativa, destaca el caso del grupo etario entre 13 y 17 años el cual paso de un 76,4\% en el 2006 al $85,9 \%$ en el 2013, con una tasa de matrícula bruta de 90,5 en ese año, así como la disminución de la deserción nacional de un 13,2\% en el 
2006 a un 9,9\% en el año 2013. Sin embargo, el dato más importante radica en la disminución de la brecha en equidad educativa por ingresos; en tanto, la asistencia a la educación formal de la población entre los 13 y 17 años aumentó, en el quintil más bajo, de un $64 \%$ a un $79 \%$, mientras que en el quintil más alto el aumento fue de un $92 \%$ a un $93 \%$, disminuyendo la brecha educativa entre ricos y pobres de un 44\% en el año 2003 a un $20 \%$ en el año 2013. Todo esto es un reflejo de la preocupación del Estado por restaurar, al menos en el corto plazo, los índices de permanencia y cobertura registrados en el país durante la década de 1970 y, al mismo tiempo, se puede reconocer el incremento de cobertura educativa como un mecanismo para disminuir la crisis de legitimidad de la primera década del siglo XXI.

Por su parte, entre el 2006 y el 2014 se da un incremento significativo de los Colegios Técnicos, en tanto de un total de 882 centros educativos de secundaria (públicos, privados y subvencionados) que tenía Costa Rica en el 2013, 127 instituciones de ellos eran Colegios Técnicos Profesionales frente a los 696 académicos. Se evidencia también un aumento de la matrícula de 62 093 mil estudiantes en el 2006 hasta 95 mil estudiantes en el 2014, junto a la apertura de nuevas especialidades como las secciones nocturnas. Además, las asignaturas del área técnica también son reformadas. Estos esfuerzos son coherentes con el MPS y su objetivo de armonizar las demandas laborales con la formación especializada que debe brindar el Estado. La comprensión de la relación entre MPS y la formación de mano de obra para los sectores empresariales debe ser comprendida para aminorar el riesgo de la simplificación del fenómeno ligándolo única y exclusivamente a posturas neoliberales.

Las reformas y las acciones enunciadas anteriormente, e implementadas entre el 2006-2014, son pertinentes en el marco de los cuatro grandes retos establecidos por el Congreso Ideológico del Partido Liberación Nacional en el año 2005, a saber:

Un reto social, que consiste en hacer de la educación un instrumento eficaz para cerrar la brecha entre las clases sociales, crear nuevas oportunidades de ascenso social y suscitar la participación activa de todos en la solución solidaria de los problemas. Un reto económico, que consiste en que la educación haga posible que contemos con los recursos humanos idóneos para elevar la competitividad y productividad de la economía nacional de manera que nos podamos integrar exitosamente en la economía mundial. Un reto ético, para que la educación fortalezca aquellos valores y actitudes que le den a lo económico y lo social un sentido altruista, inspirador, incorruptible y 
humanista. Y un reto ecológico, para que la educación promueva y

reproduzca un desarrollo que armonice las relaciones entre el ser

humano y la naturaleza (Partido Liberación Nacional, 2005, p. 54).

Así, las reformas en las dos administraciones de Leonardo Garnier pueden ser asumidas como parte del Modelo Pedagógico Socialdemócrata, tanto en relación con las características del modelo entre 1957 y 1985 como con la reformulación implícita en el Congreso Ideológico del año 2005. Sin embargo, esta tesis contradice una lectura generalizada entre sectores progresistas costarricenses relacionada con la alineación neoliberal de la propuesta educativa posterior a la crisis de la década de 1980. Debido a lo anterior resulta necesario ampliar acerca de las implicaciones de esas reformas para los sectores progresistas.

\section{Las implicaciones del MPS para el sector progresista costarricense}

Las administraciones de Leonardo Garnier (2006-2010, 2010-2014) como Ministro de Educación Pública implicaron la reinstauración del MPS tanto en el diseño curricular (perfil de ser humano, las reformas académicas y extra académicas y reforma en evaluación) como en las políticas de inversión, su relación con el modelo económico y conceptualización-operacionalización del sistema educativo como herramienta de distribución de la riqueza y movilizadora social. A lo anterior es importante agregar sus posiciones sobre la importancia del arte en la educación, el centro educativo como centro de identidad, la necesidad de la educación sexual y de la afectividad, la educación para la libertad y la lucha contra el miedo y el verticalismo en el sistema educativo o conferencias con una narración educativa ligada a reivindicaciones históricas de la pedagogía crítica y movimientos progresistas. En su conjunto todos estos elementos representaron una posición pedagógica mucho más profunda de los postulados del MPS y difícilmente separables de las propuestas del progresismo educativo.

Adicionalmente, la administración Garnier Rímolo debe considerarse a raíz de la constitución de una nueva política de Estado en el área Educativa que, por primera vez en las últimas cuatro décadas, adquiere continuidad en la siguiente administración (2014-2018) a partir del análisis del Plan Nacional de Desarrollo Alberto Cañas Escalante 2014-2018 presentado por el gobierno del Partido Acción Ciudadana.

Para el Progresismo Educativo, la premisa de reconocer la administración Garnier Rímolo como una reinstauración del Modelo Pedagógico Socialdemócrata puede ser interpretada como una invisibilización del neoliberalismo 
vigente en el sistema educativo y una rendición frente al proyecto hegemónico. No obstante, aceptar la premisa desarrollada en el presente ensayo no implica invisilizar el modelo hegemónico Neoliberal impulsado en Costa Rica desde la década de los ochenta, en cambio exige no analizar la implementación de dicho modelo desde una posición reproduccionista.

La implementación de un proyecto hegemónico (con el respectivo modelo económico) es un proceso complejo de luchas entre los grupos de poder defensores de dicho modelo, los grupos de poder con intereses contrarios, los grupos de presión defensores de un determinado status quo y los grupos progresistas que poseen una agenda alternativa.

El presente ensayo reconoce la existencia del modelo Neoliberal al mismo tiempo que reconoce su implementación alejada de la narración oficial (y de sectores del progresismo costarricense) que caracteriza la implementación del mismo como homogénea y carente de oposición. El modelo Neoliberal no logró ser implementado uniformemente en Costa Rica al punto de que podría ser factible darle otra denominación a lo que comúnmente hemos denominado Estado Neoliberal en tanto, para lograr su viabilidad el grupo dominante, el grupo político representante del proyecto hegemónico, los grupos de presión y la sociedad civil establecieron pactos explícitos e implícitos, llegando a mantener dentro de la estructura del Estado Costarricense a instituciones y políticas públicas no coherentes con el modelo neoliberal. Por lo tanto, es posible observar al sistema educativo como escenario de resistencias (Bourdieu y Passeron, 2001) capaz de implementar un proyecto educativo no lineal con un proyecto hegemónico tampoco coherente con las premisas educativas brindadas desde un determinado modelo económico.

El progresismo educativo requiere visibilizar y cuestionar al modelo educativo imperante desde aristas mucho más complejas que el reduccionismo de una oposición radical a todo proceso educativo implementado en los últimos años bajo el supuesto de que responde a un modelo neoliberal. Lo contrario exige un amplio proceso de reflexión y acción para lograr distinguir la paja del trigo; es decir, comprender, valorar y utilizar determinados elementos del Modelo Pedagógico Socialdemócrata para la construcción de un Modelo Pedagógico Crítico, Revolucionario o Alternativo y suprimir aquellos elementos ligados con un conservadurismo o pertenecientes al Ajuste Pedagógico Neoliberal. Acá sería también oportuno generar un debate sobre la creación de la legitimidad institucional del modelo económico, así como de la disminución e institucionalización de los conflictos generados por las distorsiones del mercado y la verdadera educación brindada en la contextualización curricular; es decir, aquella educación construida en las aulas que puede ser opuesta al proyecto hegemónico o al proyecto educativo progresista.

Por último, el sector educativo progresista requiere establecer las primeras aproximaciones del diseño curricular del Modelo Pedagógico Crítico (u otro nombre que vaya a tomar según sus características), que vendría a sustituir 
al MPS con el fin de poder establecer las características educativas vitales a reformar, aquellas que serían pactadas, las que son necesarias a mediano plazo para la consolidación del nuevo modelo y las que se mantendrían, así como las acciones legales y políticas necesarias para su mantenimiento y expansión. Dichos elementos, de los que careció el Ajuste Pedagógico Neoliberal, han sido los que ahora el MPS ha logrado crear, consolidar y utilizar.

\section{Conclusiones}

Lo analizado en el presente artículo permite establecer la necesidad de realizar nuevas interpretaciones de la historia educativa más allá de la visión cronológica clásica. Ello posibilitará desarrollar análisis y propuestas a partir de elementos internos al sistema educativo; en este caso, la división a partir de la evolución del currículo costarricense como sistema de control ligado a un proyecto hegemónico.

Establecer una lectura histórica desde el currículo, comprendido como un hecho cultural que trasciende los programas de estudio, permite analizar crítica y contextualizadamente al modelo pedagógico. En el caso del presente ensayo, este analizó el Modelo Pedagógico Socialdemócrata (MPS) y el Ajuste Pedagógico Neoliberal (APN). En el primero se ha demostrado la existencia de marcos conceptuales (concepto de educación, visión, misión, función social y económica, concepción de docente y estudiante, perfil de salida del estudiante y perfil de ser humano) y reguladores (inversión en educación, índices de cobertura, programas de equidad, malla curricular, asignaturas, ofertas académicas y ampliación de la infraestructura) de la educación costarricense elaborados como parte de un proyecto económico pos Guerra Civil (Estado Desarrollista), además del desarrollo del currículo como área teórica y técnica funcional dentro de la nueva estructura educativa (construida a partir de la tecnificación extrapolada de los principios empresariales), una institución cultural clave para la movilidad social y la creación de una plataforma de legitimidad de los diversos procesos y acciones implementadas como parte del proyecto hegemónico.

Como resultado de la crisis económica, que afectó a Costa Rica a finales de la década de 1970 e inicios de la década de 1980, el proyecto de Estado Desarrollista pierde legitimidad social al tiempo que se presenta una reconfiguración de las élites económicas con un creciente sector ligado a la propuesta ideológica de un Estado Neoliberal. El presente ensayo concluye que el surgimiento del Modelo o Estado Neoliberal en Costa Rica no implicó la construcción de un Modelo Pedagógico Neoliberal, por el contrario, desarrolló un APN (1986-2005) constituido por reformas parciales a los marcos conceptuales y reguladores de la educación en el MPS. 
La reinstauración del MPS se construye a partir del debilitamiento del APN. EI quinquenio entre el año 2000 y 2005 fue el referente porque durante ese período se manifestaron luchas sociales y fracturas institucionales (surgimiento de nuevos partidos y aumento del abstencionismo) que obligan al Partido Liberación Nacional (PLN) a realizar un Congreso Ideológico en el cual se restablecen los pilares del modelo educativo impulsado como parte del MPS y que sería reflejado en las siguientes dos administraciones.

La designación del señor Leonardo Garnier Rímolo como Ministro de Educación Pública, en las administraciones del Partido Liberación Nacional 20062010 y 2010-2014, estableció las condiciones políticas para operacionalizar el currículo oculto socialdemócrata ya implícito en las algunas de las publicaciones semanales realizadas por el señor Garnier en la columna Sub/versiones en el periódico La Nación entre el año 2002 y 2005.

Lo anterior ha sido denominado, en el presente artículo, como reinstauración del MPS en el tanto que implica un reforzamiento de pilares de los marcos conceptuales y reguladores de la educación. En los marcos conceptuales se desarrolla la concepción de educación como herramienta institucional para la movilidad social y creación de legitimidad, la formación de una ciudadanía vinculada con la patria, las ciencias, el arte, la comunidad y la producción (Fines de la Educación). Además se reinstaura la función social del sistema educativo como integrador y formador de estudiantes para un modelo productivo que exige bilingüismo así como competencias técnicas y competencias para la vida. Con respecto a los marcos reguladores, se reforman los programas de estudio de diversas asignaturas y se desarrollan los programas extra académicos. Igualmente la inversión en infraestructura, mobiliario y los programas de equidad reciben los mayores aumentos porcentuales y nominales desde la década de 1970. Es pertinente agregar que la oferta educativa se diversifica, se amplía la cantidad de Colegios Técnicos Profesionales y reforman reglamentos-directrices emanadas durante la década anterior.

Asumir la tesis de la reinstauración del MPS implica, para el progresismo educativo costarricense, superar el análisis tradicional basado en la premisa lineal-reproduccionista de que un Estado Neoliberal posee un sistema educativo Neoliberal (lo que obliga a una oposición radical a todo proceso de reforma educativa). Lo aquí expuesto obliga a analizar la relación Proyecto Hegemónico- Estado-Modelo Económico-Sistema Educativo como una interacción compleja, dinámica e incluso opuesta, con escenarios de resistencia o incongruencias. Por lo tanto, las reflexiones y las acciones progresistas deben hilvanar los elementos constitutivos de su propuesta pedagógica con elementos del MPS, al tiempo que deben caracterizar claramente los elementos del APN que serán rechazados en su propuesta. 


\section{Referencias}

Apple, M. (1997). Política cultural y educación. Madrid: Morata.

Apple, M. (1996a). Educación y poder. Barcelona: Paidós.

Apple, M. (1996b). El conocimiento oficial. La educación democrática en una era conservadora. Madrid: Paidós.

Bourdieu, P; y Passeron, J. (2001). La reproducción. Elementos para una teoría del sistema de enseñanza. Madrid: Popular.

Camacho, J. (2005). Un siglo de educación costarricense: 1814-1914. San José: EUCR.

Dengo, M. (2011). Educación costarricense. San José: EUNED.

Fernández, M. (2002). Políticas socialdemócratas de igualdad de oportunidades educativas: las experiencias de González y Miterrand. Revista Española de Ciencia Política, 22, 39-65

Freire, P. (1997). Educación y participación comunitaria. En: Castells, M; Flecha, R; Freire, P; Giruoux, H; Macedo, D y Willis, P. Nuevas perspectivas críticas en educación. Barcelona: Paidós.

Freire, P. (1990). La naturaleza política de la educación. Cultura, poder y liberación. Barcelona: Paidós.

Freire, P. (1984). Pedagogía del Oprimido. Madrid: Siglo XXI.

García, I. (2011). Formación de la clase media en Costa Rica. Economía, sociabilidad y discursos políticos (1890-1950). Tesis no publicada de Maestría Académica en Historia, Universidad de Costa Rica, San José, Costa Rica.

Garnier, L. (2002a). El arte no es un queque. La Nación. Recuperado noviembre 22, 2014, de http://leonardogarnier.com/articles/subversiones/el-arte-no-es-unqueque-252

Garnier, L. (2002b). Comer Juntos. La Nación. Recuperado noviembre 22, 2014, de http://leonardogarnier.com/articles/subversiones/comer-juntos$\underline{236}$

Garnier, L. (2002c). Malestar de nuestro tiempo. La Nación. Recuperado noviembre 22, 2014, de http://leonardogarnier.com/articles/subversiones/el-malestar-de-nuestrotiempo-240 
Garnier, L. (2002d). Dar ganas de leer. La Nación. Recuperado noviembre 22, 2014, de http://leonardogarnier.com/articles/subversiones/darganas-de-leer-221

Garnier, L. (2004). Luces y Sombras. La Nación. Recuperado noviembre 22, 2014, de http://leonardogarnier.com/articles/subversiones/luces-ysombras-428

Garnier, L. (2005a). La ciudadanía es como el sexo. La Nación. Recuperado noviembre 22, 2014, de http://leonardogarnier.com/articles/subversiones/la-ciudadan-es-comoel-sexo-541

Garnier, L. (2005b). Universalizar la secundaria. La Nación. Recuperado noviembre 22, 2014, de http://leonardogarnier.com/articles/subversiones/universalizar-lasecundaria-580

Garnier, L. (2006). El único antídoto. La Nación. Recuperado noviembre 22, 2014, de http://leonardogarnier.com/articles/subversiones/el-nico-ant$\underline{\text { doto- } 607}$

Gimeno, J. (2001). El currículo: una reflexión sobre la práctica. Madrid: Morata.

Gimeno, J. (1998). Poderes inestables en educación. Madrid: Morata.

Gimeno, J. (1997). Pedagogía por objetivos. Obsesión por la eficiencia. Madrid: Morata.

Giroux, H. (2006). La escuela y la lucha por la ciudadanía. Pedagogía crítica de la época moderna. México, D.F: Siglo XXI.

Giroux, H. (1997). Cruzando límites. Trabajadores culturales y políticas educativas. Barcelona: Paidós.

Giroux, H; \& McLaren, P. (1998). Sociedad, cultura y educación. Madrid: Niño y Dávila Editores.

Habermas, J. (2008). Facticidad y validez. Sobre el derecho y el Estado democrático de derecho en términos de teoría del discurso. Madrid: Trotta

Hidalgo, A. (1998). La forzada apertura comercial y el modelo neoliberal de desarrollo en Costa Rica. Revista de Ciencias Sociales, 78-79, 61-74.

Hindes, B. (2002). La ciudadanía neoliberal. Revista Mexicana de Ciencias Políticas y Sociales, 45, 107-131. 
Kemmis, S. (1998). El currículo: más allá de la teoría de la reproducción. Madrid: Morata

Korten, A. (1997). Ajuste Estructural en Costa Rica. Una medicina amarga. San José: Departamento de Ecuménico.

La Nación. (2014).Ocho años de avance educativo. La Nación. Recuperado noviembre 20, 2014, de http://www.nacion.com/opinion/editorial/anosavance-educativo_0_1397660230.html

Lichstenztejn, S. (1988). Políticas económicas neoliberales en América Latina. Revista Centroamericana de Economía, 8(9), 125-148.

McLaren, P. (1995). Pedagogía crítica y cultura depredadora. Políticas de oposición en la era posmoderna. Barcelona: Paidós.

Ministerio de Educación Pública. (2014). Memoria Institucional 2006-2014. La educación subversiva. Atreverse a construir el país que queremos. San José: s.e.

Miranda, G. (2010). La fundación del Partido Liberación Nacional y el origen del proyecto político educativo socialdemócrata en Costa Rica. Una aproximación hermenéutica crítica. Revista de Ciencias Sociales, 130, 185-213.

Miranda, G. (2007). Política curricular, crisis de legitimación y hegemonía neoliberal. Una visión desde la sociología de la educación critica. Revista de Ciencias Sociales, 115, 13-34.

Miranda, G. (2001). Capitalismo global y cambio educativo. Los fundamentos estructurales e ideológicos de la política educativa neoliberal. Revista Educare, 4(7), 13-42.

Molina, I. (2007). Educación y sociedad en Costa Rica: de 1821 al presente (una historia no autorizada). Diálogos Revista Electrónica de Historia, 8(2), 149-356.

Molina, I; \& Palmer, S. (2000). Educando a Costa Rica: alfabetización popular, formación docente y género (1880-1950). Costa Rica: Porvenir.

Partido Liberación Nacional (2005). V Congreso Nacional Daniel Oduber Quirós Una Costa Rica Integrada por las Oportunidades. San José: s.e.

Pérez, M. y González, Y. (1991). De la crisis financiera al proyecto neoliberal: la educación superior en Costa Rica. Káñina, XV, 341-348.

Rovira, J. (2000). Estado y política económica en Costa Rica: 1948-1970. San José: EUCR. 
Taba, H. (1974). Elaboración del currículo. Buenos Aires: Troquel.

Torres, J. (2001). Educación en tiempos del Neoliberalismo. Madrid: Morata.

Torres, J. (1998). El currículo oculto. Madrid: Morata

Toruño, C. (2010). Fundamentos curriculares de la ciudadanía en un Estado Neoliberal: el caso del sistema educativo costarricense. Actualidades Investigativas en Educación, 10 (2), 1-25.

Toruño, C. (2011). ¿Es neoliberal la reforma en el MEP? Diario Digital El País. Recuperado diciembre 01, 2014, de http://www.elpais.cr/frontend/noticia_detalle/3/39612

Tyler, R. (1973). Principios básicos del currículo. Buenos Aires: Troquel.

Vargas, L. (2002). Costa Rica, 1985-1997: liberalización y ajuste estructural o la autodestrucción del neoliberalismo. San José: EUNED. 